\title{
KOŽNA PREOSETLJIVOST I VENTILACIJSKA FUNKCIJA KOD RADNIKA U KOŽARSKOJ INDUSTRIJI
}

\author{
SKIN SENSIBILITY AND VENTILATION FUNCTIONS AT THE WORKERS IN THE TANNERY \\ INDUSTRY
}

\author{
Rodna Jordanova, Olivera Jordanova
}

Cilj: Cilj ispitivanja je da se determinira kožna preosetljivost sa specifičnih alergena sa radne sredine $i$ da se proceni suodnos između kožne preosetljivosti $i$ ventilasijske funkcije kod radnika $u$ kožarskoj industriji.

Materijal i metode: Ispitivana je grupa od 80 radnika, od muškog i ženskog pola, direktno uključeni u prerade kože, sa prosječne dobi od X=45.28土 5.93god., i prosječne profesionalne ekspozicije od $X=19.64 \pm 6.54$ god., a kao kontrolna grupa izabrani su 32 radnika iz raznih profila koji ni su uključeni $u$ procesu prerade kože. Kog ispitivanih radnika urađeni su kožni testovi sa specifičnih alergena sa radnog mesta po prick metodi. Ispitivana je samo prva faza disanja-plućne ventilacije sa spirometriskog testiranja, pri što je korišćen aparat SPIROSET-3000. Za statistička analiza podataka korišćen je Student- $t$-test $i \chi^{2}$-test.

Rezultati: Sa istraživanjem utvrdili smo pozitivne kožne preosetljivosti od I tipa na dva specifična alergena iz radnog mjesta, kod 29(36.25\%) od eksponiranih radnika. Sa visok stepen alergiske preosetljivosti izdvajaju se alergeni, dlake psa kod 14(17.50\%) radnika, dlake mačke kod 10(12.50\%), dlake ovce i pamuk po 8(10.00\%)radnika, vune 5(6.25\%), a zatim slede alergeni dlake zeca i sintetika po $3(3.75 \%)$ radnika. Dokazalo se da eksponirani kožni radnici češće reaguju sa pozitivnih kožnih prick testova na apliciranih specifičnih alergena sa radnog mesta, u odnos na neeksponiranih radnika. Pri proceni soodnosa između kožne preosetljivosti i hroničnog efekta zaprašenosti na ventilacijske funkcije, utvrđeno je da hronično djelovanje zaprašenosti na ventilasijske funkcije, statistički značajno češće je kod eksponiranih kožarskih radnika sa pozitivnih kožnih testova, u odnos na neeksponiranih radnika za spirometriskog parametra MMF (p<0.05), dok kod eksponiranih kožarskih radnika sa negativnih kožnih testova, hronično djelovanje zaprašenosti na ventilasijske funkcije, statistički značajno češće je za spirometriskih parametra VC, FEV $, M M V, M M F, F E F_{75} i F E F_{50}(p<0.01 ; p<0.001)$, u odnos na neeksponiranih radnika.

Zaključak: S našeg istraživanjem dokazalo se da krznena prašina može da uzrokuje oštečenje plućne funkcije kod radnika u kožarskoj industriji. Radnici kod kojih utvrdit će se respiratorno obolenje, pretstavljuju rizična grupa i trebaju se navreme otstraniti iz radnih mjesta gde su direktno uključeni u procesu prerade kože, sa prekin profesionalne ekspozicije.

Ključne rïječi: ventilacijska funkcija, kožarska industrija, kožni prick testovi, kožarski radnici,profesionalna ekspozicija.

Kompleksna struktura krznene prašine koja je organska prašina, pri preradi kože ,inhalirana $u$ plućima kako aerosol, može uzrokovati različiti respiratorni efekt u uslovima profesionalne ekspozicije. Kod ispitivanja koja su vršena iz više autora, utvrđena je visoka prevalencija respiratornih simptoma i uticaj zaprašenosti na redukcije ventilacijske funkcije $(1,2,3,4,5)$. Sa razvojem medicine, izmenili su se saznanja, a paralelno sa njih razvijaju se klinička i teoretska istraživanja koja omogućuju definiranje plućnjih oboljenja sa profesionalnom patologijom, kod radnika koji su eksponirani organskoj prašini $(6,7)$. Profesionalna alergijska oboljenja, koji se odnose na bolesti uzrokovani sa ekspozicijom supstancije iz radne sredine (specifični profesionalni agensi), u čijoj 
patogenezi imunoalergiski fenomeni imaju važnu ulogu $(8,9)$. Svetska zdravstvena organizacija uz pomoć posebne radne grupe, 1996 godine, donela je preporuke za klasifikaciju senzibiliziračkih agensa na koži i plućnih puteva u radnoj i životnoj sredini, za unificiran pristup na prepoznavanje i evaluaciju alergiskog potencijala ovih supstancija (10).

\section{Cilj:}

Da se determinira kožna preosetljivost sa specifičnih alergena radne sredine i da se proceni suodnos između kožne preosetljivosti i ventilasijske funkcije kod radnika u kožarskoj industriji.

\section{Materijal i metode:}

Istraživanjem je obuhvaćeno 80 radnika, koji su direktno uključeni u preradi kože, i to $46(57.5 \%)$ od muškog pola i $34(42.5 \%)$ od ženskog pola, sa prosječne dobi od $X=45.28 \pm 5.93$ god., (u raspon od 31-60god.) i prosječne profesionalne ekspozicije od $\mathrm{X}=19.64 \pm 6.54$ god., ( u raspon od 5-40god). Kao kontrolna grupa izabrani su 32 radnika iz raznih profila koji ni su uključeni u procesu prerade kože, slične po uzrasti sa eksponiranih. Svih 80 radnika testirani su sa kožni testovi po prick metodi sa specifičnih alergena sa radnog mjesta: dlake ovce, vune, dlake zeca, dlake psa, dlake mačke, sintetika i pamuk. Alergeni su pripremljeni u Institutu za imunologiji i virusologiji “Torlak"-Beograd. Aplikacija alergena je na volarnoj strani podlaktice po prick metodi, sa ubod preko kapi alergena na $2 \mathrm{~cm}$ od jednoj do drugoj kapi, a rezultati su pročitani po 15-20minuta. Kao negativna kontrolna proba je apliciran fiziološki rastvor, a kao pozitivna kontrola histamin, vo istoj količini i na isti način kako alergeni. Interpretacija rezultata kožnih testova je prema Međunarodnog konsenzusa kožnih alergoloških proba od 1994godine, gde je unificiran prick metod, pri što je čitanje reakcije spored metod, sa sumiranje veličine na največi i njemu normalni prečnik u mm, pri što suma u mm na kvadekuli da je $\geq 3 \mathrm{~mm}$. Ispitivana je samo prva faza disanja-plućne ventilacije sa spirometriskog testiranja, pri što je korišćen aparat SPIROSET-3000. Spirometriska merenja su vršena pred početak radnog vremena i na kraj radnog vremena. Određivani su osnovni spirometriski parametri: vitalni kapacitet (VC), forsiran ekspirijumski protok-volumen $\mathrm{u}$ prvoj sekundi $\left(\mathrm{FEV}_{1}\right)$, maksimalna minutna ventilacija (MMV). Vrijednosti spirometriskih parametra su koregirani sa BTPS factor (European Coal and Steel Organisation)- Evropska zajednica za ugljen i čelik, uzimajući u predvid pol, životno doba i visina ispitanika (11). Vrijednosti testova za VC i FEV manji od $80 \%$ referentnih vrijednosti spored ECCS smetaju se za patološki. Za promjene u malih dišnih puteva koriščeni su testovi krive-protok volume (flow volume) $\mathrm{FEF}$ 75, $\mathrm{FEF}_{50}, \mathrm{FEF}_{25}$. $\mathrm{Za}$ evaluacije parametra protočnosti u malih dišnih puteva od krive-protok volume (flow volume), rezultati manji od $70 \%$ referentnih vrijednosti smetaju se za patološki (12). Za statistička analiza podataka korišćen je Student- $\mathrm{t}$ - test i $\chi^{2}$-test. Vrijednosti na $\mathrm{p}<0.05$ su smetane za signifikantne pri statističke analize rezultata.

\section{Rezultati:}

Svi testirani radnici su pokazali karakterističnu pozitivnu kožnu reakciju na histamina, a ni jedan na fiziološki rastvor. Od ukupno 80 testiranih radnika u kožarskoj industriji $29(36.25 \%)$ su sa pozitivne kožne preosetljivosti od I tipa na dva specifična alergena iz radnog mjesta, što ukazuje na visok stepen specifične senzibilizacije (tabela1).

Pri evaluaciju rezultata u odnos alergogene moći, sa največi intenzitet kožne preosetljivosti izdvajaju se alergeni, dlake psa kod $14(17.50 \%)$ radnika, dlake mačke kod 10(12.50\%), dlake ovce i pamuk po $8(10.00 \%)$ radnika, vune $5(6.25 \%)$, a zatim slede alergeni dlake zeca i sintetika po 3(3.75\%) radnika (slika1). Dokazalo se da eksponirani kožni radnici češće reaguju sa pozitivnih kožnih prick testova na apliciranih specifičnih alergena sa radnog mesta, $u$ odnos na neeksponiranih radnika. Pri proceni soodnosa između kožne preosetljivosti i ventilacijske funkcije kod eksponiranih radnika, određivan je hronični efekt zaprašenosti na plućne ventilacije, pri što utvrđeno je da hronično djelovanje zaprašenosti na ventilasijske funkcije, statistički značajno češće je kod eksponiranih kožarskih radnika sa pozitivnih kožnih testova, u odnos na neeksponiranih radnika za spirometriskog parametra MMF $(\mathrm{p}<0.05)$, dok kod eksponiranih kožarskih radnika sa negativnih kožnih testova, hronično djelovanje zaprašenosti na ventilasijske funkcije, statistički značajno češće je za spirometriskih parametra $\mathrm{VC}, \mathrm{FEV}_{1}, \mathrm{MMV}, \mathrm{MMF}$, 
$\mathrm{FEF}_{75}$ i $\mathrm{FEF}_{50}(\mathrm{p}<0.01 ; \mathrm{p}<0.001), \mathrm{u}$ odnos na neeksponiranih radnika (tabela2).

\section{Diskusija:}

Postoje veci broj faktora iz radne sredine koji na različiti nacin i sa različiti stepen uticaju na plućni sistem eksponiranih radnika.U odnos na problem organske prašine, $\mathrm{u}$ uslovi profesionalne ekspozicije, naš akcent je bio vrz ocjene uticaja na veči broj senzibiliziračkih noksi na plućni sistem kod eksponiranih radnika kožarske industrije. Od sprovedena istraživanja kod 42 radnika od ženskog pola u kozarskoj industriji, pri što je utvrđena prevalencija na rane pozitivne kožne reakcije na antigene životinskig dlaka za lasica $10 \%$, lisica i jagnje 7\%, vizon 5\% i kinesko jagnje, domaća lisica i kinesko tele $2 \%$. Prevalencija hroničnih respiratornih simptoma je registrirana kod radnika sa pozitivnih kožnih testova (3). Slične podatke smo dobili i mi, gde od 80 testiranih radnika u kožarskoj industriji, 29(36.25\%) radnika pokazali su pozitivnu kožnu preosetljivost na specificne alergene sa radnog mjesta. Sa najviši stepen alergiske preosetljivosti izdvajaju se alergeni, dlake psa kod $14(17.50 \%)$ radnika, dlake mačke kod $10(12.50 \%)$, dlake ovce i pamuk po $8(10.00 \%)$ radnika, vune $5(6.25 \%)$, a zatim sljede alergeni dlake zeca i sintetika po $3(3.75 \%)$ radnika. Utvrđeno je da eksponirani kožni radnici češće reaguju sa pozitivnih kožnih prick testova na apliciranih specifičnih alergena sa radnog mjesta, $u$ odnos na neeksponiranih radnika. Slične podatke su dobili u istraživanje provedeno kod 54 radnika od ženskog pola u kožarskoj industriji, pri što je utvrđena viša prevalencija na rane pozitivne kožne reakcije na antigene zivotinjskig dlaka kod lisice i jagnje 7\%, lasica $10 \%$, kinesko jagnje i vizon 5\%, kinesko tele i domašna lisica $2 \%$. Pri proceni soodnosa između kožne preosetljivosti i ventilacijske funkcije kod eksponiranih radnika, određivan je hronični efekt zaprašenosti na plućne ventilacije, kod radnika sa pozitivnih i negativnih koznih prick testova sa spefificnih alergena sa radnog mjesta. Utvrđeno je da hronično djelovanje zaprašenosti na ventilasijske funkcije, statistički značajno češće je kod eksponiranih kožarskih radnika sa pozitivnih kožnih testova, u odnos na neeksponiranih radnika za spirometriskog parametra MMF $(\mathrm{p}<0.05)$, dok kod eksponiranih kožarskih radnika sa negativnih kožnih testova, hronično djelovanje zaprašenosti na ventilasijske funkcije, statistički značajno češće je za spirometriskih parametra $\mathrm{VC}, \mathrm{FEV}_{1}, \mathrm{MMV}$, MMF, $F F_{75}$ i FEF $_{50}(p<0.01 ; p<0.001)$, u odnos na neeksponiranih radnika. Slični rezultati su dobiveni pri ispitivanjem u kojim je sleđena reakcija kože, prema pojavi hroničnih respiratornih simptoma $\mathrm{i}$ prema ventilacijske funkcije kod radnika izloženih različitih organskih aerosola u kožarskoj industriji. Radnici izloženi specifičnih alergena sa radnog mjesta imali su mnogo češće pozitivnih kožnih prick testova na apliciranih specifičnih alergena sa radnog mjesta, u odnos na neeksponiranih radnika. Radnici sa pozitivnih kožnih prick testova na apliciranih specifičnih alergena sa radnog mjesta, češće su se žalili na hronične respiratorne simptome, nego one sa negativnih kožnih prick testova, iako razlike nikad nisu imali statističku značajnost (13).

\section{Zaključak:}

Rezultati našeg istraživanja su pokazali da postoji viši stepen profesionalnog rizika u pojavi patoloških respiratornih pojava i entiteta koji su povezani za profesionalnu ekspoziciju, sa direktnom izloženosti na profesionalne nokse $\mathrm{u}$ procesu prerade kože. Krznena prašina može da uzrokuje oštečenje plućne funkcije kod eksponiranih radnika u kožarskoj industriji. Radnici kod kojih utvrdit će se respiratorno obolenje, pretstavljuju rizična grupa i trebaju se navreme otstraniti iz radnih mjesta gde su direktno uključeni u procesu prerade kože, sa prekin profesionalne ekspozicije, za da se spreči evaluacija samog oboljenja kon ireverzibilne promjene i respiratorne insuficijencije.

\section{Literatura:}

1. Kara inska-Bislimovska J. Organski prav, ekspozicija i respiratoren efekt. Vo: Zbornik na rezimea od II Kongres na makedonsko respiratorno združenie. Ohrid, 1997:132-4.

2. Rylander R, Jacobs RR. Organic dust: exposure, effects and prevention. Chicago II.Lewis publishing Inc, 1994:7-11.

3. Žuškin E, Pokrajac D, Ivankovic D, Kanceljak B, Tonković-Lojović M, Godnić-Cvar J, Turčić N. Respiratory function in fur-processing workers. Arh Hig Rada Toksikol 1989 Dec; 40 (4): 347-54.

4. Colloff MJ, Ayres J, Carswell F, et all. The control of allergens of dust mites and domestic pets: a 
position paper. Clin Exp Allergy, 1992;22(Suppl.2):1-28.

5. Žuškin E, Kanceljak B, Stilinović 1, Schachter EN, Kopjar B. Immunological status and respiratory findings in furriers. Am J Ind Med 1992; 21 (3): 433-41.

6. Žuškin E, Skuric Z, Kanceljak B, Pokrajac D, Schachter EN, Witek TJ Jr. Respiratory symptoms and lung function in furriers. Am $\mathrm{J}$ Ind med 1988;14(2):187-96.

7. Žuškin E, Kanceljak B, Stilinovic̀ L, Godniċ-Cvar J, Tonković-Lojovic M. Immunologic status, respiratory symptoms and ventilatory function in fur processing workers. Arh Hig Rada Toksikol 1990 Jun; 41 (2): 175-85.

8. Gimenez C. Fouad K. Choudat D. Laureillard J. Bouscaillou P. Leib E. Chronic and acute respiratory effects among grain mill workers. International Archives of Occupational \& Environmental Health, 1995; 67(5):311-5.
9. Tačević S, Bogić M, Tanurdžić S. Profesionalne alergijske bolesti pluća. Revija rada 1995 (specijalno izdanje); 71-82.

10. Asthma management and prevention. A Practical Guide for Public health Officials and health care Professionals. NHLB/WHO Workshop Report. Publication No 95-3659 A, Bethesda, Maryand:1995.

11. Commission des Communautes Europeenes, CECA. Aide memoire pour la pratique de l' examen de la fonction ventilatoire par la spirographie. Collection D' Hygiene et de Medicine du Travail, No 11, Luxembourgh, 1971.

12. Cherniack RM, Raber MB. Normal standards for ventilatory function using an automated wedge spirometer. Am Res Respir Dis 1972;106:38-46.

13. Žuškin E. Schachter EN. Kanceljak B. Mustajbegovic J. Witek TJ. Immunological and respiratory reactions in workers exposed to organic dusts. International Archives of Occupational \& Environmental Health, 1994; 66(5):317-24.

\begin{tabular}{|l|c|c|c|c|c|c|c|}
\hline & \multicolumn{2}{|c|}{$\begin{array}{c}\text { POZITIVNI } \\
\text { prick test }\end{array}$} & \multicolumn{2}{c|}{$\begin{array}{c}\text { NEGATIVNI } \\
\text { prick test }\end{array}$} & \multicolumn{2}{c|}{ UKUPNO } & $\begin{array}{c}\text { SIGNIFI- } \\
\text { KANTNOST }\end{array}$ \\
\cline { 2 - 8 } & BROJ & $\%$ & BROJ & $\%$ & BROJ & $\%$ & $2-$ test \\
\hline $\begin{array}{l}\text { ISPITIVANA } \\
\text { GRUPA }\end{array}$ & 29 & 36.25 & 51 & 63.75 & 80 & 100.00 & $\mathrm{X}=0.85$ \\
\hline $\begin{array}{l}\text { KONTROLNA } \\
\text { GRUPA }\end{array}$ & 8 & 25.00 & 24 & 75.00 & 32 & 100.00 & $\mathrm{X}<3.841$ \\
\hline UKUPNO & 37 & 33.00 & 75 & 67.00 & 112 & 100.00 & $\mathrm{p}>0.05$ \\
\hline
\end{tabular}

Tabela 1. Prevalencija kožne preosetlivosti I tipa, specifičnih alergena, kod Ispitivane i Kontrolne grupe radnika 


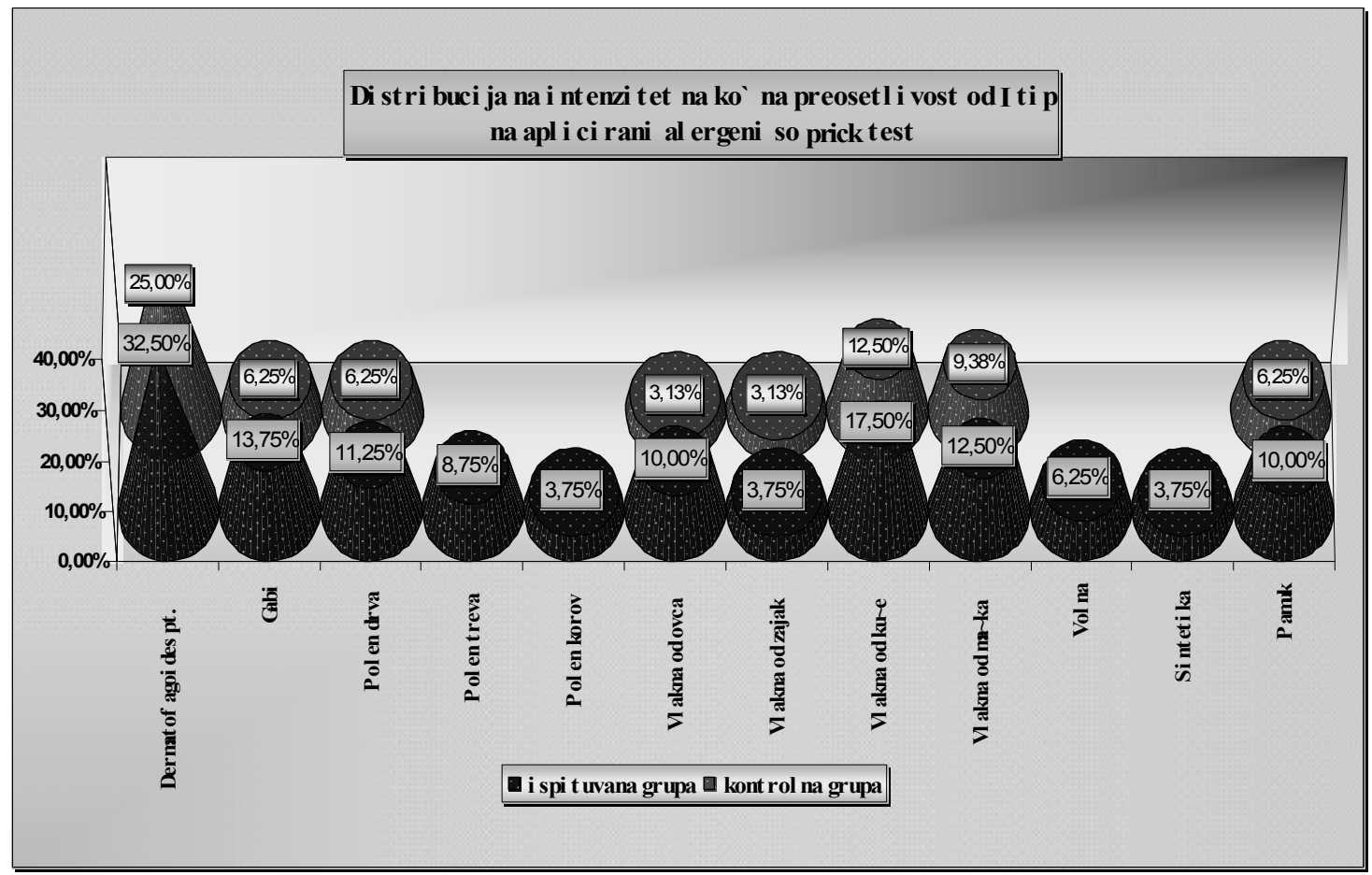

Slika 1.Distribucija intenziteta kožne preosetljivostiod I tipa na aplicirani alergeni sa kožnog prick testiranja

\begin{tabular}{|l|l|l|l|l|l|}
\hline TEST & $\begin{array}{l}\text { negat. prick test. na } \\
\text { spec. } \\
\text { IG (51) }\end{array}$ & $\begin{array}{l}\text { negat. prick } \\
\text { test. na spec. alergeni } \\
\text { KG (24) }\end{array}$ & $\begin{array}{l}\text { SIGNIFIKANTNOST } \\
\text { t } \text { - test }\end{array}$ \\
\hline VC (L) & $4.08 \pm 0.94$ & $5.49 \pm 0.99$ & $5.86^{*}$ & 3.5 & $\mathrm{p}^{*<0.001}$ \\
\hline FEV1 (L) & $3.41 \pm 0.83$ & $4.19 \pm 0.73$ & $4.10^{*}$ & 3.5 & $\mathrm{p}^{*}<0.001$ \\
\hline MMV (L/min.) & $101 \pm 18$ & $126 \pm 17$ & $5.83^{*}$ & 3.5 & $\mathrm{p}^{*}<0.001$ \\
\hline MMF (L/sek.) & $4.73 \pm 1.07$ & $5.58 \pm 1.28$ & $2.83^{*}$ & 2.65 & $\mathrm{p}^{*}<0.01$ \\
\hline FEF75 (L/sek.) & $7.60 \pm 1.85$ & $8.98 \pm 1.61$ & $3.29^{*}$ & 2.65 & $\mathrm{p}^{*}<0.01$ \\
\hline FEF50 (L/sek.) & $5.11 \pm 1.50$ & $6.28 \pm 1.41$ & $3.25^{*}$ & 2.65 & $\mathrm{p}^{*}<0.01$ \\
\hline FEF25 (L/sek.) & $2.16 \pm 0.81$ & $2.27 \pm 0.78$ & 0.58 & 2.00 & $\mathrm{p}>0.05$ \\
\hline
\end{tabular}

Tabela 2. Vrijednosti parametra ventilaciske funkcije između Ispitivane $i$ Kontrolne grupe radnika sa negativnih prick testova na specifičnih alergena iz radnog mjesta

Summery: Aim. The aim of the study is to determinate the skin sensibility with the specific allergens from the working environment and to estimate the correlation between the skin sensibility and ventilation function at the workers in the tannery industry.

Material and method. There were made an examination on 80 workers ( man and woman), directly involved in the leather treatment, with average age $X=45.28 \pm 5.93$ years, and average professional exposition of $X=19.64 \pm 6.54$ years, and as a control group were taken into account 32 workers from different profiles, who were not included in leather treatment. At the examination group of workers were made a skin test with specific allergens from the working place with prick method. There were examination only a first phase of breathing - the pulmonary ventilation with spirometric test, which is used apparatus SPIROSET - 3000. For processing data is using a lot of statistical method: Student's-t tests and $\chi^{2}$ - test.

Results. With the examination we were determinate a positive skin sensibility of tip I, of the two specific allergens from the working places, at 29 (36.25\%) at the exposed workers. With the high degree of the allergic sensibility was separate allergens, fibre of dog $14(17.50 \%)$ workers, fibre of cat 10 $(12.50 \%)$, fibre of sheep and cotton $8(10.00 \%)$ workers, wool 5 (6.25\%) after that, following the 
allergens, a fibre of rabbit, synthetic 3 (3.75\%) workers. It was proved that, the exposed skin workers, more often reat with positive skin prick tests of the using specific allergens from the working place, against the non-exposed workers. At the corelation between the skin sensibility and chronical effect to cover with dust of the ventilation functions were statistic more significant at the exposed tanerry workers with possitive skins tests againts, non-exposed workers, for spirometrical parameter $M M F(p<0.05)$, while at the exposed tannery workers with negative skin tests the chronical influence at the cover with dust of the ventilation function is statistic more significant for spirometrical parameters $V C, F E V_{1}, M M V$, $M M F, F_{75}$ and $F E F_{50}(p<0.01 ; p<0.001)$, against non-exposed workers.

Conclusion. With our examination we proved that the skin dust can raised demaged the respiratory functions at the workers in tannery industry. At the workers in who will be determinate a respiratory disease, they request a risk group, and it was necessary to stay out of his working places, where they are directly involved in the proces of the leather treatment, as well as to stop they are professional exposition.

Key words: ventilation function, tannery industry, skin prick tests, tannery workers, professional exposition.

Prim.D-r.Rodna Jordanova, M-r.sci.

Specijalist medicine rada

Adresa: ul.Petre Prlicko br.22-1/10 1400 Veles,

Republika Makedonija

Tel. mobilni : +38972208830

E-mail: rodnajordanova@yahoo.com 